\title{
Gastric Emptying in Prematures of Isocaloric Feedings with Differing Osmolalities
}

\author{
MYRON SIEGEL, EMANUEL LEBENTHAL, ${ }^{(26)}$ WILLIAM TOPPER, BRIDGET KRANTZ, AND \\ PHILIP K. LI \\ Department of Pediatrics, State University of New York at Buffalo, Division of Gastroenterology \& Nutrition, \\ Children's Hospital of Buffalo, Buffalo, New York, USA
}

\begin{abstract}
Summary
The role of osmolar load in the regulation of gastric emptying time was studied in 10 healthy premature infants. Two isocaloric infant feedings of similar composition with mean osmolalities of 279 and $448 \mathrm{mOsm} / \mathrm{kg}$ were compared. Emptying was studied over 120 min by the double sampling marker dilution technique and by a single aspiration of the feeding at $30 \mathrm{~min}$. Similar gastric emptying times were noted for both formulas with approximately half of the initial gastric contents remaining at $30 \mathrm{~min}$. The secretory response to the two meals during the first $30 \mathrm{~min}$ after feeding was compared by measuring the secretions present in the stomach during that time. The mean secretory response to the feedings did not differ significantly and was less than $2.5 \mathrm{ml}$ in both cases. In general, a biphasic pattern of gastric emptying with a rapid early emptying phase was noted with both feedings. This study, therefore, provides evidence that when isocaloric feedings with similar composition are used, osmolar load does not play a significant role in the regulation of gastric emptying in premature infants. This study also demonstrates that differences in osmolality do not significantly affect the secretory response to a meal in the stomach of the premature infant.
\end{abstract}

\section{Speculation}

By developing a better understanding of the factors which regulate gastric emptying time in infancy, a physiologic basis for dealing with clinical problems such as gastroesophageal reflux or inadequate gastric emptying by premature infants may be developed. These patients could benefit from infant formulas which are nutritionally sound but empty more rapidly than formulas currently available. The present data indicate that osmolar load is not an important consideration in the feeding of these patients. The role of other factors such as the specific constituents of a feeding or its caloric density remain to be determined.

The manner in which an infant empties food from his stomach can have a significant effect on his nutrition and health. Infants with gastroesophageal (GE) reflux, severe enough to cause failure to thrive or recurrent pulmonary disease, have delayed gastric emptying compared with infants with mild GE reflux (11). Problems in nutritional support can occur when residual volumes from previous feedings limit the amount offered to a premature infant. A better understanding of the factors which control gastric emptying might improve the methods of dealing with these problems.

Studies in adults and infants have demonstrated that the type of food offered can significantly effect emptying. Hunt and Stubbs (17) analyzed a number of studies in adults and concluded that the caloric density of a meal was the major determinant in the regulation of gastric emptying. Despite this conclusion, Cavell (6) demonstrated in premature infants that an adapted cow's milk formula emptied significantly more slowly than human milk even though the feedings were isocaloric. Therefore, in infancy factors other than caloric density appear to play a role in regulating gastric emptying. Pascale et al. (23) compared emptying of three isocaloric formulas and found that the high osmolar feeding resulted in higher gastric residuals. The authors concluded that "formula osmolar load appears to exert the greatest influence on gastric retention in low birth weight infants" (23). However, these feedings all differed in carbohydrate, fat and protein composition as well as osmolar load making it difficult to assess the reason for the variation in gastric emptying. The purpose of this study was to examine two isocaloric feedings of very similar composition but differing osmolality to better assess the role of osmolar load in regulating gastric emptying in the premature infant.

It is possible that feedings of differing osmolality could affect the infant's secretory response to a meal. Therefore, this study also measured the volume of secretions found in the stomach in response to the two feedings.

\section{MATERIALS AND METHODS}

Patients. Ten premature infants on nasogastric feedings (6 males and 4 females) were studied. Mean gestational age at birth was $30.7 \mathrm{wk}$ with a range of 26 to $34 \mathrm{wk}$. The infants were 1 to $9 \mathrm{wk}$ of age at the time of the study corresponding to 33 to $39 \mathrm{wk}$ gestational age. The mean weight during the study was $1888 \mathrm{~g}$ ranging from 1683 to $2275 \mathrm{~g}$. These values represent the average weight of each patient during the 4 days of the study. All infants were considered to be growing premature infants without major medical problems at the time of the study. None were receiving oxygen or ventilatory support. Four were receiving theophylline for apnea and bradycardia. Two patients were receiving antibiotics; one recovering from an episode of sepsis 1 week earlier, the other was recovering from pneumonia. All were considered appropriate for gestational age at birth. Gestational age was determined by the method of Ballard et al. (2).

This study protocol was approved by the Human Research Committee of Buffalo Children's Hospital. In all cases, informed consent was given by the parents.

Formulas. Neo-Mull-Soy and Cho-Free with glucose (Syntex Corporation) were used in this comparison. These feedings are essentially the same except for the carbohydrate used. Neo-MullSoy contains sucrose. Glucose was added to the Cho-Free in an amount necessary to have both formulas contain $6.4 \%$ carbohydrate. Details of formula composition are listed in Table 1. Osmolality was measured by the vapor pressure technique (3).

Feeding volume. All patients received about $22 \mathrm{ml} / \mathrm{kg}$ during the study. Volumes ranged from 20.8 to $22.4 \mathrm{ml} / \mathrm{kg}$. All patients were studied on four occasions and each patient received the same volume at each of his four feedings.

Measurement of gastric emptying. Comparison of gastric emptying was done by two techniques. Part 1 used the double sampling marker dilution method of George (10). This method allows for continuous sampling during the entire emptying process and is based on the principle that the contents of a container can be 
Table 1. Data on infant formulas

\begin{tabular}{|c|c|c|}
\hline & Neo-Mull-Soy & $\begin{array}{l}\text { Cho-Free with Glu- } \\
\text { cose }\end{array}$ \\
\hline Protein & $\begin{array}{c}\text { soy protein isolate } \\
1.8 \mathrm{~g} / 100 \mathrm{ml}\end{array}$ & $\begin{array}{c}\text { soy protein isolate } \\
1.8 \mathrm{~g} / 100 \mathrm{ml}\end{array}$ \\
\hline Fat & $\begin{array}{l}\text { soybean oil } \\
3.5 \mathrm{~g} / 100 \mathrm{ml}\end{array}$ & $\begin{array}{l}\text { soybean oil } \\
3.5 \mathrm{~g} / 100 \mathrm{ml}\end{array}$ \\
\hline Carbohydrate & $\begin{array}{l}\text { sucrose } 6.4 \mathrm{~g} / 100 \\
\mathrm{ml}\end{array}$ & glucose $6.4 \mathrm{~g} / 100 \mathrm{ml}$ \\
\hline Caloric density & $20 \mathrm{Cal} / \mathrm{oz}$ & $20 \mathrm{Cal} / \mathrm{oz}$ \\
\hline \multicolumn{3}{|l|}{$\begin{array}{l}\text { Caloric distribution } \\
\% \text { calories }\end{array}$} \\
\hline protein & $11 \%$ & $11 \%$ \\
\hline fat & $49 \%$ & $49 \%$ \\
\hline carbohydrate & $40 \%$ & $40 \%$ \\
\hline $\begin{array}{l}\text { Osmolality }{ }^{1} \text { (mOsm/ } \\
\mathrm{kg} \text { ) }\end{array}$ & $279 \pm 12^{2}$ & $448 \pm 11^{2}$ \\
\hline
\end{tabular}

${ }^{\prime}$ Mean values obtained by averaging data from all feedings tested. $\mathrm{Kg}$ represents kilograms of $\mathrm{H}_{2} \mathrm{O}$ in the formulas.

${ }^{2} \pm$ S.D.

measured by observing how the concentration of a marker is increased with the addition of a small amount of concentrated marker. Samples are taken before and after the concentrated marker is added. The formula is derived as follows: $V_{1}$, volume to be determined; $C_{1}$, initial concentration of marker in $V_{1} ; V_{2}$, volume of concentrated marker added to $V_{1} ; C_{2}$, concentration of added marker; $\mathrm{C}_{3}$, final concentration of the marker; the mass of marker in $V_{1}$ is given by $m_{1}=V_{1} C_{1}$; the mass of marker in $V_{2}$ is given by $m_{2}=V_{2} C_{2}$. The original George equation is then derived from the principle:

$$
\mathrm{m}_{1}+\mathrm{m}_{2}=\mathrm{m}_{3}
$$

Therefore $\mathrm{V}_{1} \mathrm{C}_{1}+\mathrm{V}_{2} \mathrm{C}_{2}=\left(\mathrm{V}_{1}+\mathrm{V}_{2}\right) \mathrm{C}_{3}$ and

$$
\mathrm{V}_{1}=\mathrm{V}_{2} \frac{\left(\mathrm{C}_{2}-\mathrm{C}_{3}\right)}{\left(\mathrm{C}_{3}-\mathrm{C}_{1}\right)}
$$

However, the theoretical accuracy of the technique at small volumes is improved by accounting for the marker and volume removed at the first sampling. Cavell (6) used the modification of this formula which accounts for these changes but did not provide the derivation. The derivation is as follows: since marker is removed at the first aspiration, actually $m_{1}+m_{2}=m_{3}+m_{4}$ where $m_{3}$ is the total mass of marker provided by $m_{1}+m_{2}$ excepting the marker removed at the first sampling. $M_{4}$ is the marker removed at the first sampling. If each of the two samples removed at each measuring period equals one-half the volume added, there will be no net change in volume due to sampling. The marker removed at the first sampling will then be:

$$
1 / 2 \mathrm{~V}_{2} \mathrm{C}_{1}=\mathrm{m}_{4}
$$

In addition, the true volume present at the time of the second sampling will be: $V_{1}+V_{2}-1 / 2 V_{2}$ due to the removal of $1 / 2 V_{2}$ at the first sampling. Therefore:

$$
\mathrm{m}_{3}=\left(\mathrm{V}_{1}+\mathrm{V}_{2}-1 / 2 \mathrm{~V}_{2}\right) \mathrm{C}_{3}
$$

and

$$
\begin{gathered}
\mathrm{m}_{1}+\mathrm{m}_{2}=\mathrm{m}_{3}+\mathrm{m}_{4} \\
\mathrm{~V}_{1} \mathrm{C}_{1}+\mathrm{V}_{2} \mathrm{C}_{2}=\left(\mathrm{V}_{1}+\mathrm{V}_{2}-1 / 2 \mathrm{~V}_{2}\right) \mathrm{C}_{3}+1 / 2 \mathrm{~V}_{2} \mathrm{C}_{1} \\
\mathrm{~V}_{1}\left(\mathrm{C}_{3}-\mathrm{C}_{1}\right)=\mathrm{V}_{2}\left(\mathrm{C}_{2}-\mathrm{C}_{3}\right)+1 / 2 \mathrm{~V}_{2}\left(\mathrm{C}_{3}-\mathrm{C}_{1}\right) \\
\mathrm{V}_{1}=\mathrm{V}_{2} \frac{\left(\mathrm{C}_{2}-\mathrm{C}_{3}\right)}{\left(\mathrm{C}_{3}-\mathrm{C}_{1}\right)}+1 / 2 \mathrm{~V}_{2}
\end{gathered}
$$

$\mathrm{V}_{1}$ represents the total gastric contents in the stomach including both meal and secretions at the time of measurement.

The marking material used in this study was polyethylene glycol (PEG) 4000. The initial concentration in the feeding was $5 \mathrm{~g} /$ liter.
The concentrated marker solution used during the study was 50 $\mathrm{g} /$ liter PEG added to the feeding being tested.

In part 1 of this study, each patient was given one feeding of each formula in random order on consecutive days at approximately the same time each day. The studies were done $3 \mathrm{~h}$ after the previous meal. Prior to each feeding the stomach was washed out with saline. Feedings were given via nasogastric tube over $2-$ $3 \mathrm{~min}$. The infants were then placed in the prone position and samples were taken every $20 \mathrm{~min}$ as timed from the completion of the feeding. At each $20 \mathrm{~min}$ interval, $2.5 \mathrm{ml}$ of fluid was removed. Five ml of concentrated marker was then added and mixed by withdrawing and reinserting syringefuls 12 times. A second $2.5 \mathrm{ml}$ sample was then removed. This procedure was continued until less than $2.5 \mathrm{ml}$ of fluid could be removed or at $120 \mathrm{~min}$ whichever came first. At the final sampling, the entire stomach contents were aspirated and the stomach was washed with $5 \mathrm{ml}$ aliquots of saline until clear. The final volume was determined by measuring the total PEG obtained in the aspirate and washout fluid and dividing by the concentration in the aspirated sample. This is the technique of volume measurement described by Hunt and Spurrell (12).

Part 2 of the study involved one feeding of each formula in random order except that in this case the entire gastric contents were aspirated at $30 \mathrm{~min}$. Total volume was assessed as in the final aspiration of part 1 by washing out the stomach with $5 \mathrm{ml}$ aliquots of saline and dividing total PEG obtained by the PEG concentration in the initial aspirate. In order to avoid a rapid decline of PEG to undetectable levels by the repeated saline washouts, the starting PEG concentration in this portion of the study was $20 \mathrm{~g} /$ liter rather than $5 \mathrm{~g} /$ liter. This technique did not allow the analysis of gastric emptying over time but did provide a means of comparing emptying by an alternative method to see if both methods provided similar results.

In both parts of the study, PEG concentration was measured according to the technique of Malawer and Powell (21).

Secretions. The secretory response to the introduction of a meal into the stomach was measured by the drop in PEG concentration at the first sampling which occurred at $20 \mathrm{~min}$ in part 1 and at 30 min in part 2 . The volume of secretions present in the stomach was calculated as follows: $\mathrm{S}$, volume of secretions in the stomach; $\mathrm{V}_{\text {total, }}$, the total gastric contents at the time of measurement; $\mathrm{V}_{\text {meal }}$, the volume of meal only excluding the volume contributed to the total gastric contents by secretions; $\mathrm{C}_{\mathrm{A}}$, concentration of PEG in aspirated sample; $C_{M}$, concentration of PEG in original meal; $M$, total mass of PEG in the stomach; $S=V_{\text {total }}-\mathrm{V}_{\text {meal }} ; \mathrm{V}_{\text {total }}=$ $\frac{\mathrm{M}}{\mathrm{C}_{\mathrm{A}}} ; \mathrm{V}_{\text {meal }}=\frac{\mathrm{M}}{\mathrm{C}_{\mathrm{M}}}$

In the single aspiration technique $M$ was measured directly. In the double sampling technique: $M=C_{A} V_{\text {total }}$ where $C_{A}$ was the PEG concentration of the first 20 min sample and $V_{\text {total }}$ was calculated as described above using the double sampling technique.

The total secretory response to a meal is actually measured by the secretions present in the stomach plus secretions emptied with the meal. The volume of secretions emptied is represented by:

Secretions emptied $=$ Volume of gastric contents emptied Volume of meal emptied

Volume of gastric contents emptied was calculated as follows:

PEG leaving the stomach (A) = PEG in stomach initially - PEG in stomach the end of the measuring period

Average concentration of PEG leaving the stomach during the measuring period

$$
(C)_{\text {average }}=\frac{\text { PEG conc initially }+ \text { final PEG conc }}{2} \text {. }
$$

Volume of gastric contents emptied

$$
=\frac{\mathrm{A}}{\mathrm{C}_{\text {average }}}
$$


This equation was originally developed by Hunt and Spurrell (12).

When calculating the meal volume emptied, the PEG concentration in the meal, $\mathrm{C}_{\text {meal }}$ was substituted for the average PEG concentration: volume of meal emptied

$$
=\frac{\mathrm{A}}{\mathrm{C}_{\text {meal }}} \text {. }
$$

Therefore secretions leaving the stomach

$$
=\frac{A}{C_{\text {average }}}-\frac{A}{C_{\text {meal }}} \text {. }
$$

Total secretions $=$ secretions in the stomach + secretions emptied from the stomach.

Tests of validity. The marker dilution technique was tested in 2 in vitro experiments. Neo-Mull-Soy was placed in a graduated cylinder. Formula was removed and small amounts of $0.1 \mathrm{M} \mathrm{HCl}$ were added to simulate in vivo conditions. Volume was estimated as described above and compared with the measurement indicated on the graduated cylinder. The last volume estimate was based on the aspiration and washout technique. Small amounts of fluid were left in the graduated cylinder to simulate washout conditions. All data are described as the \% total volume with $41 \mathrm{ml}$ used as the total volume. This volume was selected because it represents the mean volume given to the infants in the study. The data presented in Table 2 show that the techniques used determine the actual volume with reasonable accuracy.

In each in vitro study the first sample measured was used to assess secretions present in the stomach. One and one-half $\mathrm{ml}$ of $0.1 \mathrm{M} \mathrm{HCl}$ was added in experiment 1 and $1.4 \mathrm{ml}$ was added in experiment 2 . In both cases the technique had an error of only 0.1 mi.

PEG and osmolality. The PEG used had a small but measurable effect on formula osmolality. The contributions of 5,20 and $50 \mathrm{~g} /$ liter PEG were measured in 10 of the formulas given to the infants, 5 each of Neo-Mull-Soy and Cho-Free with glucose. Five g/liter PEG added $7 \pm 4 \mathrm{mOsm} / \mathrm{kg}$ to each formula. Twenty $\mathrm{g} / \mathrm{liter}$ added $26 \pm 8 \mathrm{mOsm} / \mathrm{kg}$ and $50 \mathrm{~g} / \mathrm{liter}$ added $71 \pm 8 \mathrm{mOsm} / \mathrm{kg}$. As essentially the same amount of PEG was added to each formula during each study, it was not felt that this effect would interfere vith the results.

Complications. Two patients had single episodes of emesis during the study requiring a repeat study the following day. In one case, this occurred on day 1 so in 9 of 10 infants the actual study was completed in 4 consecutive days. Patient 10 had an episode of emesis on day 3 (day 1 of part 2) requiring a repeat of that study. Two days later he developed pneumonia delaying the last day of the study for 5 days. This patient had no signs of aspiration.

Statistics. Within-subjects analysis of variance was used in the comparison of gastric emptying times and secretions. In this way, the variability in emptying and secretory response between infants was not a factor as only the differences within each subject after receiving the two formulas were compared. Values were considered statistically significant if $P<0.05$. Regression analysis was used in the evaluation of emptying patterns.

\section{RESULTS}

Gastric Emptying. Table 3 provides data on gastric emptying in all infants for each formula as measured by the double sampling technique. It also illustrates the net difference in gastric content after feedings with each formula for each patient at all time periods. The data show on average a small excess of Cho-Free with glucose compared with Neo-Mull-Soy. This difference is not statistically significant when analyzed over the 5 time periods where data is available on each patient. Figure 1 illustrates the composite emptying pattern for both feedings using the emptying data for the 10 patients over $100 \mathrm{~min}$.

Table 4 compares the gastric volumes at $30 \mathrm{~min}$ with both feedings as measured by the single aspiration technique. It also illustrates the net difference between feedings. Again the mean values show on the average a small excess of Cho-Free with glucose compared with Neo-Mull-Soy which does not achieve statistical significance when analyzed by within-subjects analysis of variance. The mean volumes as illustrated on Figure 1 correspond well to the expected values from the emptying curves of part 1 demonstrating that by both techniques about half the initial gastric contents remained at $30 \mathrm{~min}$.

Secretions. Table 5 illustrates the volume of secretions at $20 \mathrm{~min}$ measured in part 1 and the volume at 30 min measured in part 2 . In general the volumes are relatively small although infant 4 had a comparatively large secretory response on the occasions when he received Cho-Free with glucose. At both 20 and $30 \mathrm{~min}$ the mean volume of secretions is higher in response to Cho-Free with glucose but the differences are not statistically significant. In all cases the mean secretory output is less than $2.5 \mathrm{ml}$. The negative values in Table 5 represent net absorption across the stomach wall. This effect has been reported with hypotonic solutions (13). It may have occurred in these cases but the values are so small that they could represent the intrinsic variability of the assay.

Residual volumes. All patients took at least $100 \mathrm{~min}$ to empty the feedings. Six of 10 patients had Neo-Mull-Soy present at 120 min while 7 of 10 still had Cho-Free with glucose. Only four patients out of 10 took $120 \mathrm{~min}$ to empty both formulas. The largest residual volume at $120 \mathrm{~min}$ was $7.2 \mathrm{ml}$ or $18.9 \%$ of the initial volume. As indicated by Table 3 , the mean residual volume of those patients with residuals at 120 min was less than $10 \%$ of the starting volume for both formulas.

Patterns of emptying. Figure 1 provides a composite picture of the emptying patterns obtained when all of the emptying data are combined. It demonstrates that, in general, there was a biphasic pattern of emptying with a large fraction emptied during the first 20 min followed by an essentially linear rate of emptying. Of the 20 studies performed, 15 appeared biphasic with a rapid early phase, although in 4 studies the early phase lasted 40 min rather than 20 . In these 15 cases, the average emptying rate during the early phase ( 20 or $40 \mathrm{~min}$ ) was at least 3 times the average emptying rate during the later phase. In the remaining five studies the pattern was essentially linear from the start until at least 60 min. Even in these cases, the largest volume emptied during the first $20 \mathrm{~min}$ period in four of the five studies. However, the

Table 2. Measured versus experimentally estimated volume of test meal in vitro

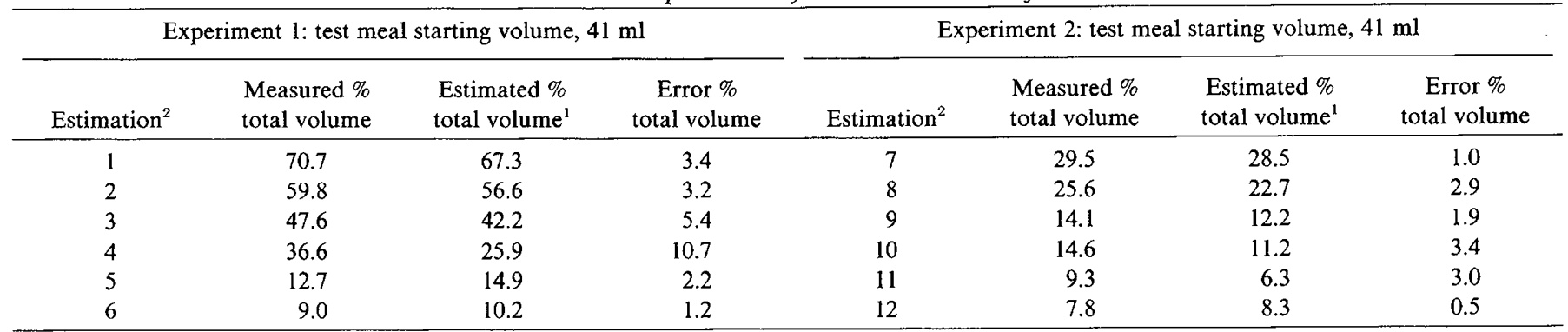

${ }^{1}$ Estimates 1-5 and 7-11 done by the double sampling technique. Estimates 6 and 12 done by aspiration and washout technique. All volumes

\footnotetext{
Estimates $1-5$ and $7-11$ done by the
expressed as $\%$ of $41 \mathrm{cc}$ starting volume.

${ }^{2}$ Mean error estimates, $1-5=5.0 \pm 3.4 \%$; mean error estimations, $7-11=2.4 \pm 1.0 \%$; mean \pm S.D.
} 
Table 3. Comparison by percent of original volume by the double sampling technique

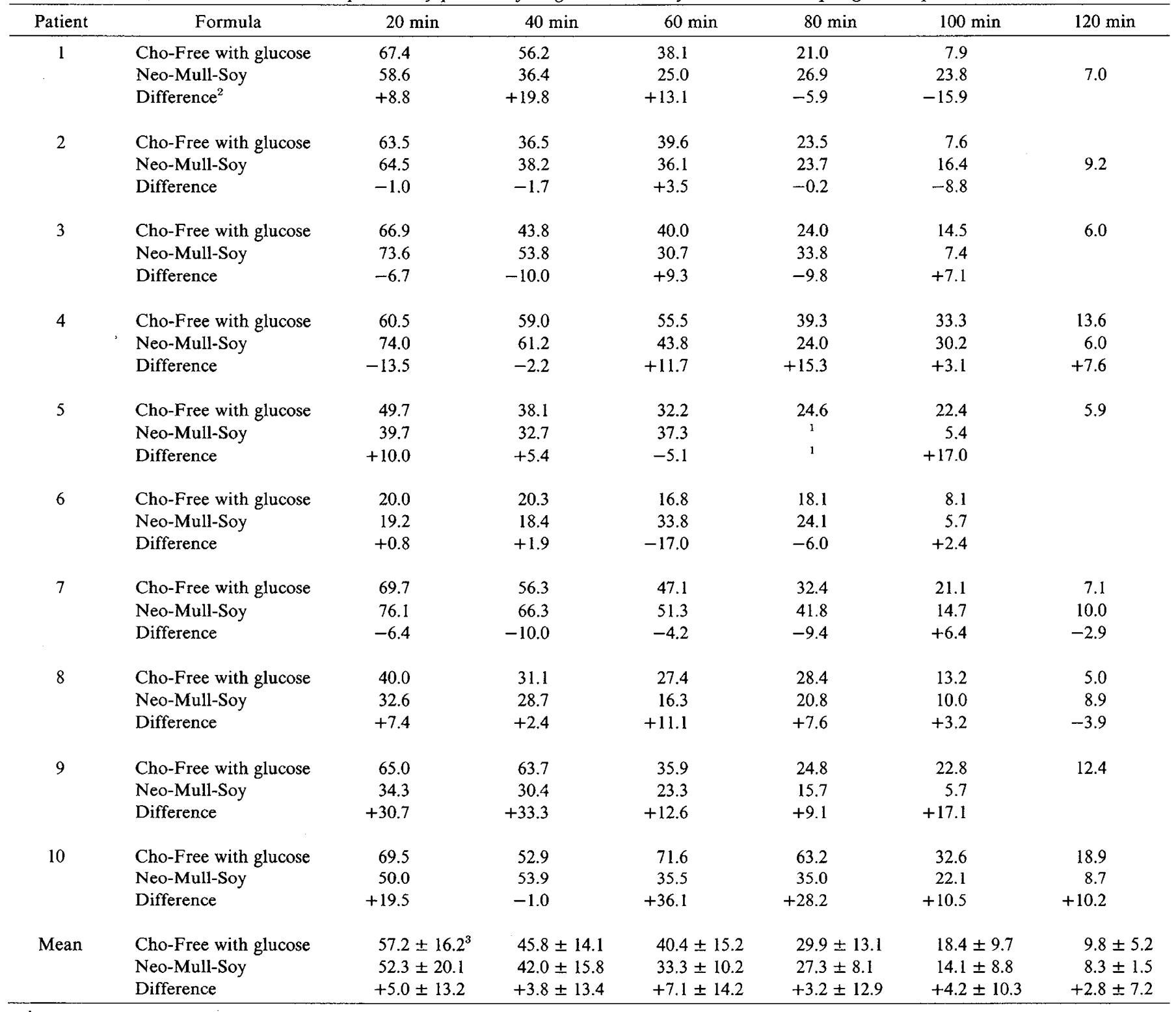

${ }^{1}$ Data unavailable.

${ }^{2}$ Positive values indicate a net larger residual volume of Cho-Free with glucose. Negative values indicate a net larger residual volume of Neo-MullSoy. Absent values at $120 \mathrm{~min}$ indicate emptying complete at $100 \mathrm{~min}$. All data expressed as \% original volume.

${ }^{3} \pm$ S.D.

difference between the first $20 \mathrm{~min}$ and later periods was relatively small and did not clearly demonstrate two distinct emptying phases.

In addition to comparing the average emptying rates early and late in the emptying process, the emptying patterns were evaluated by regression analysis. Five of the 15 biphasic patterns correlated closely $(r>0.95)$ with an exponential (first order) relationship for 100 min (i.e., the log of the gastric contents described a straight line when plotted against time). A sixth biphasic curve closely fits an exponential pattern for the first $60 \mathrm{~min}$. The remaining biphasic curves did not correlate as closely with a single mathematic function. All 5 curves, felt to be linear, fit a linear pattern for 100 min by regression analysis. Interestingly, all five of these curves also correlated with an exponential pattern for at least the first 60 min.

Figures 2, 3 and 4 illustrate the large variability of emptying patterns between infants. Figure 4 also demonstrates that periods of stasis were observed at times in the midst of the emptying process, although no such periods were noted during the first 20 min. Despite this variation, the emptying pattern of Cho-free with glucose on Figure 4 is considered biphasic as the average rate of the early phase ( $20 \mathrm{~min}$ in this case) is at least 3 times the average rate of the later phase (after $20 \mathrm{~min}$ ). In general, there was fairly good day to day agreement in the pattern of emptying for an individual patient. Figure 4 represents one of only two patients where portions of the emptying curve differed in residual volume by more than $20 \%$ of the original volume given.

\section{DISCUSSION}

The data presented here show similar gastric emptying between two isocaloric feedings that differ in osmolality by $169 \mathrm{mOsm} / \mathrm{kg}$, a relatively large difference. As the osmolality of a solution merely reflects its composition, it is not possible to alter osmolality without changing the nature of the feeding in at least one respect. In this case, the carbohydrate was changed from a disaccharide to a monosaccharide in order to increase osmolality. A number of studies in adults have demonstrated that electrolytes, monosac- 


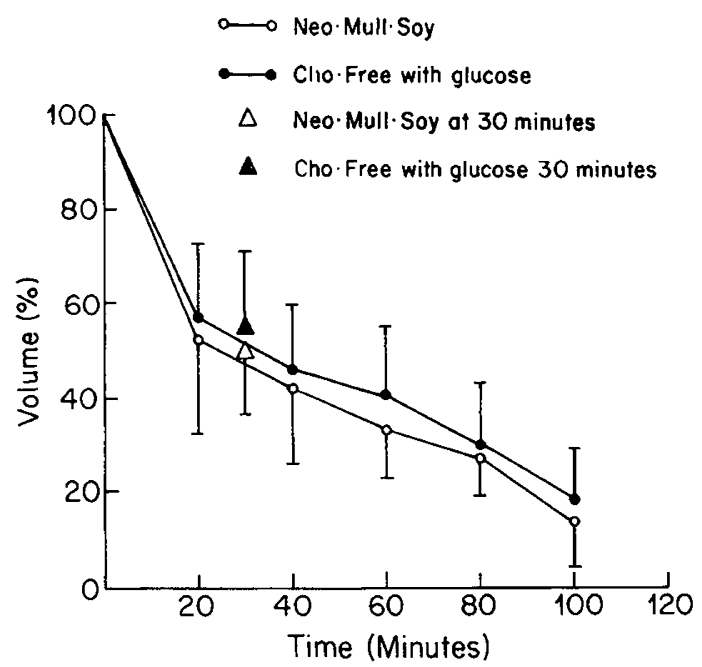

Fig. 1. Emptying patterns described by the mean residual volumes measured by the double sampling technique. Values at $30 \mathrm{~min}$ are mean residual volumes determined by the single aspiration technique. \pm (S.D.)

Table 4. Comparison of gastric emptying by the single aspiration technique at $30 \mathrm{~min}$

\begin{tabular}{cccc}
\hline Patient & $\begin{array}{c}\text { \% Original volume } \\
\text { Cho-Free with glucose }\end{array}$ & $\begin{array}{c}\text { \% Original volume } \\
\text { with Neo-Mull-Soy }\end{array}$ & $\begin{array}{c}\text { Difference be- } \\
\text { tween formulas }\end{array}$ \\
\hline 1 & 55.2 & 52.4 & +2.8 \\
2 & 69.0 & 61.6 & +7.4 \\
3 & 62.3 & 66.4 & -4.1 \\
4 & 40.2 & 40.0 & +0.2 \\
5 & 41.9 & 52.2 & -10.3 \\
6 & 29.2 & 22.4 & +6.8 \\
7 & 69.7 & 55.5 & +14.2 \\
8 & 50.5 & 37.9 & +12.6 \\
9 & 45.7 & 48.7 & -3.0 \\
10 & 83.7 & 58.7 & +25.0 \\
Mean & $54.7 \pm 16.5^{2}$ & $49.6 \pm 13.0^{2}$ & $+5.2 \pm 10.3^{2}$ \\
\hline
\end{tabular}

${ }^{1}$ Positive values indicate a larger residual volume of Cho-Free with glucose. Negative values indicate a larger residual volume of Neo-MullSoy.

\pm S.D

Table 5. Secretion data-total volume $(\mathrm{ml})$

\begin{tabular}{|c|c|c|c|c|}
\hline \multirow[b]{2}{*}{ Patient } & \multicolumn{2}{|c|}{ Data from part 1 at $20 \mathrm{~min}$} & \multicolumn{2}{|c|}{ Data from part 2 at $30 \mathrm{~min}$} \\
\hline & $\begin{array}{c}\text { Cho-Free with } \\
\text { glucose }\end{array}$ & $\begin{array}{l}\text { Neo-Mull- } \\
\text { Soy }\end{array}$ & $\begin{array}{c}\text { Cho-Free with } \\
\text { glucose }\end{array}$ & $\begin{array}{c}\text { Neo-Mull- } \\
\text { Soy }\end{array}$ \\
\hline 1 & 2.0 & 1.8 & 1.6 & 1.8 \\
\hline 2 & 1.3 & $-0.6^{1}$ & 0.1 & 0.6 \\
\hline 3 & 0.5 & 0.4 & 0.2 & -2.1 \\
\hline 4 & 9.5 & 3.3 & 9.5 & 1.7 \\
\hline 5 & 0.3 & 1.0 & 0.5 & 1.7 \\
\hline 6 & 3.0 & 1.5 & 1.9 & 0.9 \\
\hline 7 & 1.9 & 1.5 & 4.1 & 0.9 \\
\hline 8 & 2.5 & 3.0 & 1.2 & 1.8 \\
\hline 9 & -0.5 & -1.2 & -0.2 & 1.0 \\
\hline 10 & 3.3 & 0.7 & 1.2 & 1.1 \\
\hline Mean & $2.4 \pm 2.8^{2}$ & $1.1 \pm 1.4^{2}$ & $2.0 \pm 2.9^{2}$ & $0.9 \pm 1.2^{2}$ \\
\hline
\end{tabular}

${ }^{1}$ Negative values represent absorption rather than secretion of fluid.

${ }^{2} \pm$ S.D.

charides and amino acids will increasingly inhibit gastric emptying as more material is added and the osmolality of the solution increases $(7,8,14)$. Fatty acids will also inhibit emptying although the chain length as well as concentration plays a major role with long chain fatty acids having a much greater inhibitory effect than medium chain fatty acids (16). More complex sugars, starch and

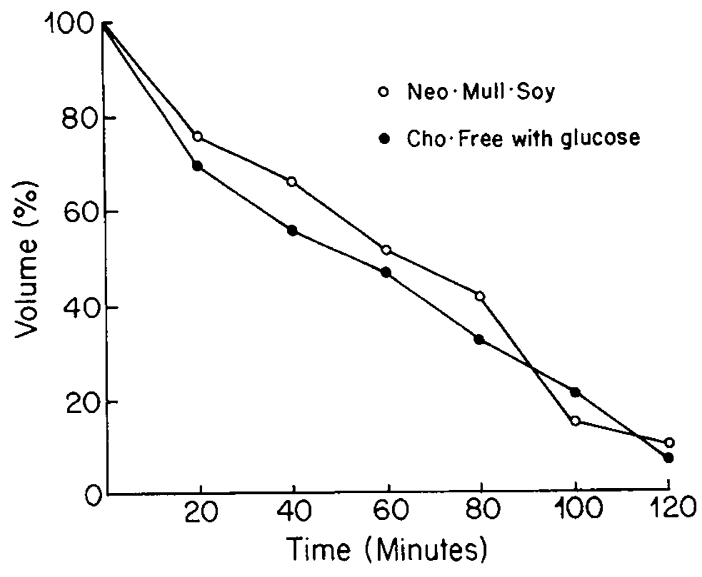

Fig. 2. Linear emptying patterns (data from patient 7).

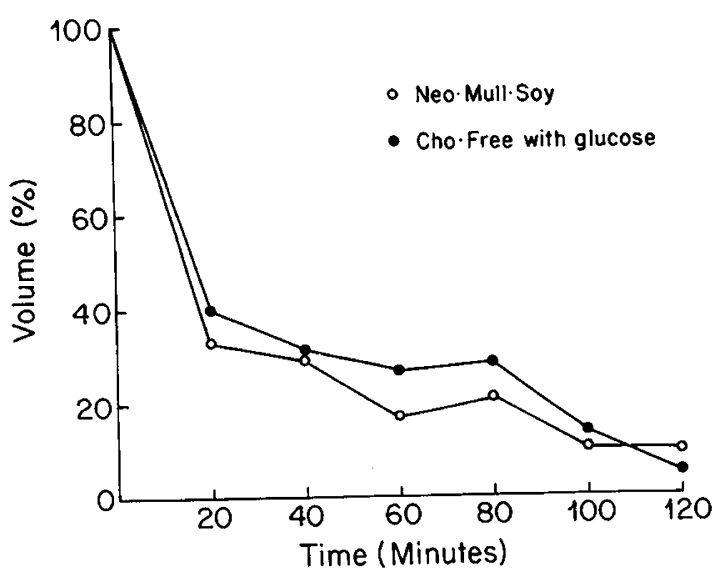

Fig. 3. Biphasic emptying patterns with a rapid early emptying phase (data from patient 8 ).

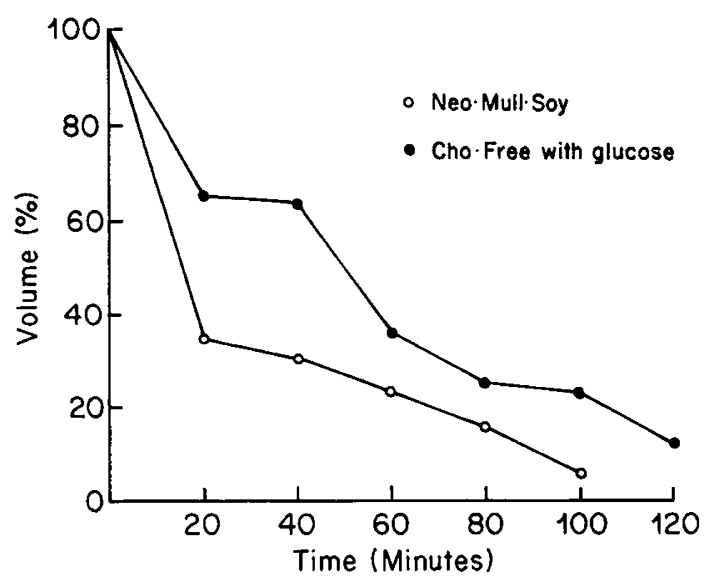

Fig. 4. Emptying data from patient 9. Pattern of Cho-Free with glucose demonstrates stasis in the midst of emptying.

protein will, in general, inhibit emptying to a degree consistent with the osmolality of the elemental components $(5,8,15)$. If this situation applies during infancy one would expect no difference in emptying between the two feedings despite the difference in osmolality as the effective osmolality of hydrolyzed sucrose is the same as glucose.

One situation in which complex foods do not effectively inhibit emptying is when there is a problem in digestion. In adults with pancreatic insufficiency or in infants with the physiologic pancreatic amylase deficiency of early infancy (20), starch does not inhibit emptying as effectively as isocaloric solutions of glucose $(19,22)$. This data implies that the "osmoreceptors" are located in 
the duodenum. As sucrose is well tolerated by premature infants (1), this issue of digestibility should not be a factor in this study.

Hunt et al. (8) have demonstrated in adults that although disaccharides are generally about as effective as monosaccharides in inhibiting emptying, differences do exist. Glucose is somewhat more effective in inhibiting emptying than sucrose. If this difference exists in infancy, it would only enhance any inhibition due to osmolar load because glucose was used in the higher osmolar feeding. Therefore, the absence of any significant difference in gastric emptying between the two feedings used in this study indicates that as in adults, osmolar load independent of caloric density does not play a major role in inhibiting gastric emptying in infancy. Whether the small mean differences in gastric volume observed in this study were due to the different inhibitory effects of sucrose and glucose seen in adults would be a matter of speculation. The differences are not statistically significant and do not increase over time as would be expected theoretically.

One possible mechanism by which a hypertonic formula could appear to empty relatively slowly would be if it induced a relatively large secretory response in the stomach increasing the measured volume of gastric contents. In this study, only small secretory volumes were obtained during the first $30 \mathrm{~min}$ after feeding with no significant differences between feedings. This result is consistent with the observation of Fordtran and Locklear (9) that when a hypertonic solution and an isotonic solution are compared, the solutions maintain their differences in osmolality in the stomach without inducing differing secretory responses that equalize osmolality. The present study does not differentiate between the stomach and salivary glands as to the major source of the infant's secretory response, but it does demonstrate that the total response is small.

There has been some disagreement in the literature about the pattern of emptying in the newborn stomach. Signer and Fridrich (24) used a cow's milk formula and found that in most patients the entire pattern best fits an exponential (first order) curve. Blumenthal, et al. (4) believed the pattern was biphasic with an initial rapid phase followed by an exponential phase. They used a $10 \%$ dextrose solution. Cavell (6) also found a biphasic pattern when he fed infants human milk, although he did not describe the slower phase by a single mathematic function. When Cavell fed infants a cow's milk formula isocaloric with human milk, the emptying pattern tended to be linear from the start or show an initial delay in emptying. The entire emptying process also took longer when infants were fed a cow's milk formula. The pattern observed with the two soy formulas used in the present study correspond best in both pattern and gastric emptying time with the results Cavell obtained with infants fed human milk.

As indicated by Cavell's study, differences in emptying may be due to the varying composition of the meals. At times, however, different mathematic descriptions of emptying curves may be used by separate observers who are actually observing similar phenomena. In the present study, examination of the composite emptying curves and most of the individual curves appear to show a biphasic pattern with a rapid early emptying phase. However, regression analysis demonstrates that the composite curves and a number of the apparently biphasic individual curves correlate closely with an exponential pattern. In addition, regression analysis also demonstrates that some emptying patterns correlate well with both linear and exponential functions. Thus, different descriptions of emptying curves may not always indicate significantly different findings. The essential message of the emptying patterns described in the present study is that in most cases a relatively large fraction of the meal was emptied during the early phase of emptying.

The data in the present study is consistent with the concept that caloric density, as regulated by the osmoreceptor system, is a determinant of gastric emptying in infancy. The demonstration by Husband and Husband (18) that a $10 \%$ dextrose solution empties more slowly than water supports this concept. However, Cavell's study showing differing emptying rates and patterns for isocaloric feedings of cow's milk formula and human milk indicate that other factors are also involved. As mentioned earlier the digestability of a feeding appears to play a role in controlling gastric emptying in both adults and infants. Whether this factor explains the difference in emptying observed by Cavell is not known at this time. The presence of biphasic emptying patterns during infancy may mean that different factors control emptying during different periods of the emptying process or perhaps the same factors have different degrees of control at various times.

Pascale et al. (23) interpreted the results of their study as showing that a high osmolar load delays gastric emptying, a conclusion which differs from the conclusion of the present study. One possible reason for this is that the difference in osmolalities in Pascale's feedings was over $300 \mathrm{mOsm} / \mathrm{kg}$ which is about twice as much as the difference in this study. Conceivably an osmolar effect might only be noted with such very large differences. Whether this is the case cannot be determined from Pascale's study because as mentioned earlier, the feedings differed in fat, protein and carbohydrate composition as well as osmolality. The data comparing cow's milk formula and human milk illustrate that feedings similar in caloric density and osmolality can empty differently apparently due to differences in composition. By limiting these differences, the present study indicates that osmolality does not effect emptying in otherwise similar feedings. It is also of note that Pascale et al. (23) used only $5 \mathrm{ml} / \mathrm{kg}$ in a feeding compared to the $22 \mathrm{ml} / \mathrm{kg}$ used in the present study. Twenty-two $\mathrm{ml} / \mathrm{kg}$ corresponds to what a growing premature infant usually receives and would be expected to better reflect conditions as they typically exist in this patient population.

In conclusion, the present study demonstrates that within the range tested, a relatively higher osmolar load does not inhibit gastric emptying of isocaloric feedings in premature infants.

\section{REFERENCES AND NOTES}

1. Antonowicz, I., and Lebenthal, E.: Developmental pattern of small intestinal enterokinase and disaccharidase activities in the human fetus. Gastroenterology, 72: 1299 (1977).

2. Ballard, J. L., Kazmaier, K., and Driver, M.: A simplified assessment of gestational age. Pediatr. Res., 11: 374 (1977)

3. Barlow, W. K.: Volatiles and osmometry. Clin. Chem., 22: 1230 (1976)

4. Blumenthal, I., Ebel, A., and Pildes, R. S.: Effect of posture on the pattern of stomach emptying in the newborn. Pediatrics, 63: 532 (1979)

5. Burn-Murdoch, R. A., Fisher, M. A., and Hunt, J. N.: The slowing of gastric emptying by proteins in test meals. J. Physiol., 274: 477 (1978).

6. Cavell, B.: Gastric emptying in preterm infants. Acta Paediatr. Scand., 68: 725 (1979)

7. Cooke, A. R., Moulang, J.: Control of gastric emptying by amino acids. Gastroenterology, 62: 528 (1972).

8. Elias, E., Gibson, G. J., Greenwood, L. F., Hunt, J. N., and Tripp, J. H.: The slowing of gastric emptying by monosaccharides and disaccharides in test meals. J. Physiol., 194: 317 (1968).

9. Fordtran, J. S., and Locklear, F. W.: Ionic constituents and osmolality of gastric and small-intestinal fluids after eating. Am. J. Digest. Dis., 11: 503 (1966).

10. George, J. D.: New clinical method for measuring the rate of gastric emptying: the double sampling test meal. Gut, 9: 237 (1968).

11. Hillemeier, A. C., Lange, R., McCallum, R., Seashore, J., and Gryboski, J. Delayed gastric emptying in infants with gastroesophageal reflux. J. Pediatr., 98: 190 (1981).

12. Hunt, J. N., and Spurrell, W. R.: The pattern of emptying of the human stomach. J. Physiol., 113: 157 (1951).

13. Hunt, J. N.: Some properties of an alimentary osmoreceptor mechanism. J. Physiol., 132: 267 (1956).

14. Hunt, J. N., and Pathak, J. D.: The osmotic effects of some simple molecules and ions on gastric emptying. J. Physiol., 154: 254 (1960).

15. Hunt, J. N.: The site of receptors slowing gastric emptying in response to starch in test meals. J. Physiol., 154: 270 (1960).

16. Hunt, J. N., and Knox, M. l.: A relation between the chain length of fatty acids and the slowing of gastric emptying. J. Physiol., 194: 327 (1968).

17. Hunt, J. N., and Stubbs, D. F.: The volume and energy content of meals as determinants of gastric emptying. J. Physiol., 245: 209 (1975).

18. Husband, J., and Husband, P.: Gastric emptying of water and glucose solutions in the newborn. Lancet, 2: 409 (1969).

19. Husband, J., Husband, P., and Mallinson, C. N.: Gastric emptying of starch meals in the newborn. Lancet, 2: 290 (1970)

20. Lebenthal, E., and Lee, P. C.: Development of functional response in human exocrine pancreas. Pediatrics, 66: 556 (1980).

21. Malawer, S. J., and Powell, D. W.: An improved turbimetric analysis of polyeth ylene glycol utilizing an emulsifier. Gastroenterology, 53: 250 (1967).

22. Mallinson, C. N.: Effect of pancreatic insufficiency and intestinal lactase defi- 
ciency on the gastric emptying of starch and lactose. Gut, 9: 737 (1968).

23. Pascale, J. A., Mims, L. C., Greenberg, M. G., and Alexander, J. B.: Gastric response in low birthweight infants fed various formulas. Biol. Neonate, 34 150 (1978)

24. Signer, E., and Fridrich, R.: Gastric emptying in newborns and young infants. Acta Paediatr. Scand., 64: 525 (1975).

25. The authors thank Ms. Rochelle Follaco, R.D., for her assistance in the prepa-

Copyright $(C) 1982$ International Pediatric Research Foundation, Inc. $0031-3998 / 82 / 1602-0141 \$ 2.00 / 0$ ration of the infant formulas and Ms. Sharon Knighton and Mrs. Mary Lou Stein for their secretarial assistance.

26. Requests for reprints should be addressed to: Dr. Emanuel Lebenthal, Division of Gastroenterology and Nutrition. Children's Hospital of Buffalo, 219 Bryant St., Buffalo, NY 14222.

27. Received for publication April 16, 1981 .

28. Accepted for publication June 22, 1981 . 